\title{
Mapping the Terrain of Homosexually-Themed Language
}

\author{
MARK McCORMACK, PhD \\ School of Sport and Education, Brunel University, Middlesex, UK
}

\begin{abstract}
In this article, I present a new model for understanding bomosexually-themed language. By detailing bow old conceptualizations of homophobic language no longer maintain beuristic utility in explaining the social dynamics of many sport and educational settings, I situate other conceptualizations of homosexuallythemed language depending on the cultural context. I argue that whether language is considered homophobic, or whether it is better conceptualized as fag discourse, gay discourse or pro-gay language, is primarily dependent on the bomohysteria of a setting. This model should enable scholars and educators to understand the operation of homosexually-themed language in society and properly evaluate the bomophobia of a setting.
\end{abstract}

KEYWORDS bomosexuality, language, discourse, gay, fag, model

A growing body of research documents that homophobia is decreasing in sport settings (Anderson, 2011; Anderson \& McGuire, 2010; Harris \& Clayton, 2007). This corresponds with a trend of decreasing homophobia in British and American cultures (Anderson, 2009; Savin-Williams, 2005; Weeks, 2007). However, the way that homosexually-themed language has changed in relation to these improving attitudes remains undertheorized. Discussions of language use normally remains fixated on whether a particular word or phrase is homophobic or not (Sanders, 2008). This simplification obscures the complex nature of homosexually-themed language and fails to engage with the range of verbal practices that have some form of homosexual content.

In this article, I propose a new model for understanding homosexuallythemed language. By critically reviewing the conceptualizations of homosexually-themed language that have proved most useful, I foreground

Address correspondence to Mark McCormack, School of Sport and Education, Brunel University, Middlesex, UB8 3PH, UK. E-mail: Mark.McCormack@Brunel.ac.uk 
the importance of cultural context in understanding the use of language with gay content. Furthermore, by introducing the concept "pro-gay language" and incorporating it into my framework, I provide a four-stage model that provides a holistic framing of homosexually-themed language. Drawing on empirical examples, I hope this model enables scholars, activists, and others who hear homosexually-themed language to more fully understand the potential meanings, intent and effects of this complex topic.

\section{USES OF HOMOSEXUALLY-THEMED LANGUAGE}

It is vital to understand the meanings and dynamics of language because it is the currency through which ideas and social norms are consolidated (Cameron \& Kulick, 2003; Kiesling, 2007). Research documents the prevalence of homophobic language in sporting settings, where homophobia limits the life experiences of sexual minorities, polices gendered behaviors, and stigmatizes nonmasculine youth (Messner, 1992; Parker, 1996). For example, Anderson (2002) demonstrates how the prevalence of homophobic language has been instrumental in many gay athletes' decisions to remain closeted, because these athletes viewed homophobic language as indicative of a hostile climate toward sexual minorities.

However, more recent research documents less damaging forms of homosexually-themed language in sport settings, and even suggests that it can have positive social effects (Anderson, 2011; McCormack \& Anderson, 2010a). Accordingly, it is necessary to explore the multiple meanings of homophobic and homosexually-themed language in order to understand the regulation and stratification of sexuality, within sport as well as in the wider culture (Plummer, 1999).

As homophobia becomes increasingly condemned in Western cultures (McCormack, 2011a; Weeks, 2007), and increasing numbers of people talk about homosexuality in positive ways, it is necessary to explore the full variety of meanings of language concerning homosexuality. However, even though a diverse body of literature exists on the topic (McCormack \& Anderson, 2010a; Pascoe, 2005; Rasmussen, 2004), understandings are all too frequently based on a simplistic conceptualization of whether language is or is not homophobic. This can lead to an exaggeration of the prevalence of homophobia because many people have been socialized into a culture where almost all colloquial language relating to homosexuality has been homophobic, making people at risk of hearing homophobia in language whether it is there or not. This is problematic because fear of homophobia (even when this fear is unwarranted) can cause gay people to stay in the closet (Anderson, 2002). In order to clarify what makes language homophobic, I argue that the literature documents two requisite features: 1) it is said with pernicious intent; and 2) it has a negative social effect. 
The first requirement of homophobic language, pernicious intent, recognizes that the speaker is intending to degrade or marginalize a person or behavior by use of the association with homosexuality. Armstrong (1997) argued that hostility and devaluation of homosexuality are "implicit in the usage of homophobic terms" (p. 328), and Thurlow (2001) highlighted the use of intent by examining "intensifiers"-additional words to a phrase that demonstrate a desire to wound a person. He found that homophobic language was accompanied by an intensifier more frequently than any other form of insult, for example, by saying "you fucking queer"' rather than "you queer."

Further evidence of the pernicious intent of homophobic language is provided by considering its role in bullying. Rivers (1996) found that verbal abuse was the most common form of bullying practice leveled at gays and lesbians, and homophobic language has also been frequently used by bullies of heterosexual students (Epstein, 1997; Rivers, 1995). Given that bullying is the marginalization of a person by more powerful peers, the frequent use of homophobic language in bullying behaviors is clear evidence of its pernicious intent.

Bullying also evidences the second component of homophobic language: It maintains negative social effect. Gay and lesbian adults often speak of the emotional trauma caused by homophobic bullying in their youth (Flowers \& Buston, 2001; Plummer, 1999), and research also highlights the negative social impact this has on students and athletes, including elevated rates of absenteeism, social isolation, and higher dropout rates in school (Warwick, Aggleton, \& Douglas, 2001), as well as lower rates of sporting participation and ostracization within sporting teams (Brackenridge, Allred, Jarvis, Maddocks, \& Rivers, 2008; Pronger, 1990). Furthermore, homophobic bullying has led to elevated levels of suicide among gay youth (D'Augelli, Hershberger, \& Pilkington, 2001), although more recent research suggests that suicide rates of lesbian, gay, bisexual, and transgender individuals are in fact comparable to urban heterosexual youth (Mustanski, Garofalo, \& Emerson, 2010).

Even when homophobic language is intended to marginalize a behavior or action rather than a person, it still reproduces homophobia because users intend to stigmatize same-sex desire (Hillier \& Harrison, 2004; Rubin, 1984). For example, using explicitly anti-gay epithets to regulate heterosexual athletes who do not conform to orthodox gender stereotypes reproduces the hierarchical stratification of all masculinities, as well as harming the recipient of the abuse. Accordingly, homophobic language can contribute to a hostile sports culture for all male youth (Hekma, 1998; Messner, 1992).

While pernicious intent and negative social effect are the two key factors that have been used to determine if language is homophobic, implicit in most academic research is an assumption that this homophobic language is said within a homophobic environment; that is, homophobic language has occurred in settings where people have homophobic attitudes and gay 


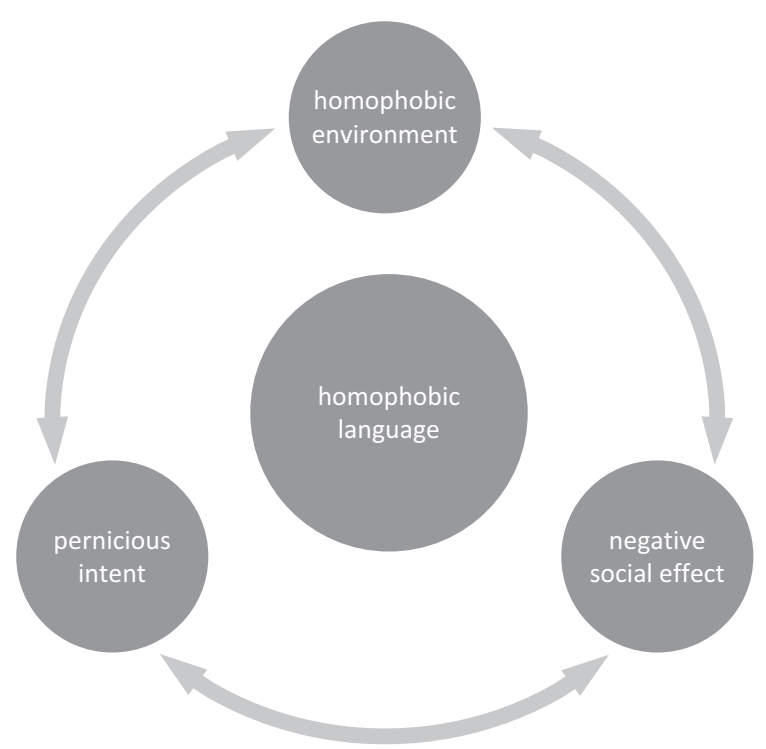

FIGURE 1 The traditional framework for understanding homophobic language. (Color figure available online.)

and lesbians are closeted or marginalized. Some scholars documented the homophobic culture (Messner, 1992), while others assumed its presence (Jackson \& Dempster, 2009; Smith, 2007).

The assumption of a homophobic environment is understandable given that the vast majority of the research on homophobic language occurred between 1980 and 2000, when British and American cultures were homophobic (Anderson, 2009; Loftus, 2001). However, the marked decrease in levels of homophobia of recent years necessitates that this assumption be made explicit for the cultural context to be recognized. Accordingly, I propose an additional factor for analyzing homophobic language-a homophobic environment. In Figure 1, I provide a pictorial framework for understanding the components of homophobic language.

This linking of environment with effect and intent helps to historically contextualize the conceptualization of homophobic language that so accurately captured the social dynamics of the 1980s and 1990s (see Anderson, 2005; Griffin, 1998; Messner, 1992). However, more recent research on the use of homosexually-themed language has highlighted complexities that do not readily fit into this framework of homophobic language.

\section{CHANGING USE OF LANGUAGE}

In 2005, Pascoe introduced the concept of "fag discourse" into discussions of homophobic language. Building on Thorne and Luria's (1986) notion of 
"fag talk," fag discourse conceptualized a gendered form of homophobia. Here, the purpose was not necessarily to regulate sexuality, but instead to regulate boys' behaviors. Importantly, Pascoe distinguished the use of the word "fag" from the use of anti-gay pejoratives such as "queer" and "poof" because fag no longer had explicit associations with sexuality for many of the participants in her study.

While the observation about the gendered nature of homophobia built on the work of British scholars of masculinity (Epstein, 1997; Mac an Ghaill, 1994), an important difference was that Pascoe (2005, 2007) documented the ways in which fag was used as a pernicious insult that regulated gender without intending to marginalize same-sex identities. For example, Pascoe (2005) highlighted that "some boys took pains to say that 'fag' is not about sexuality" (p. 336). Accordingly, fag discourse conceptualizes the use of anti-gay epithets because of antipathy toward gender nonconformity, not homosexuality.

Pascoe (2007) also highlighted that the intent was not necessarily pernicious, even if it frequently was. She commented that, "fag talk and fag imitations serve as a discourse with which boys discipline themselves and each other through joking relationships" (p. 54). This makes the notion of intent far more complex than with homophobic language. While there is always intent with fag discourse to regulate something (be it sexuality or gender, a person or a behavior), the precise intention varies. For example, it can be to wound someone, but it can also be used to castigate a behavior or even just competitively joke with friends. Indeed, use of the word fag seems almost habitual; a "compulsive" (p. 86) part of boys' interactions. It should be clear that this nuance is not recognized in the pernicious intent component of homophobic language.

Pascoe's (2007) work was considered important for the significance it had in understanding the gendered nature of homophobia. However, most academics failed to appreciate the significance of her work in documenting the changing nature of homosexually-themed language. Because pernicious intent was still sometimes evident, and because the social effect was often extremely negative, they overlooked the changes in the use of language that fag discourse conceptualized. Accordingly, despite the subtle changes in intent and effect, scholars continued to label fag discourse as part of the traditional framework of homophobic language (Bortolin, 2010; Kimmel, 2008). This would have been appropriate in the 1980s and 1990s, when the word fag was used to demonstrate disgust of homosexuality in a broader culture of extreme homophobia (Anderson, 2009), but it did not accurately capture use of the word in a different cultural context.

It is easy to read high levels of homophobia in the school where Pascoe collected data, and there were certainly highly homophobic aspects of the setting. Yet, there were also several openly gay students, as well as heterosexual students who maintained pro-gay attitudes. Indeed, Pascoe (2007) 


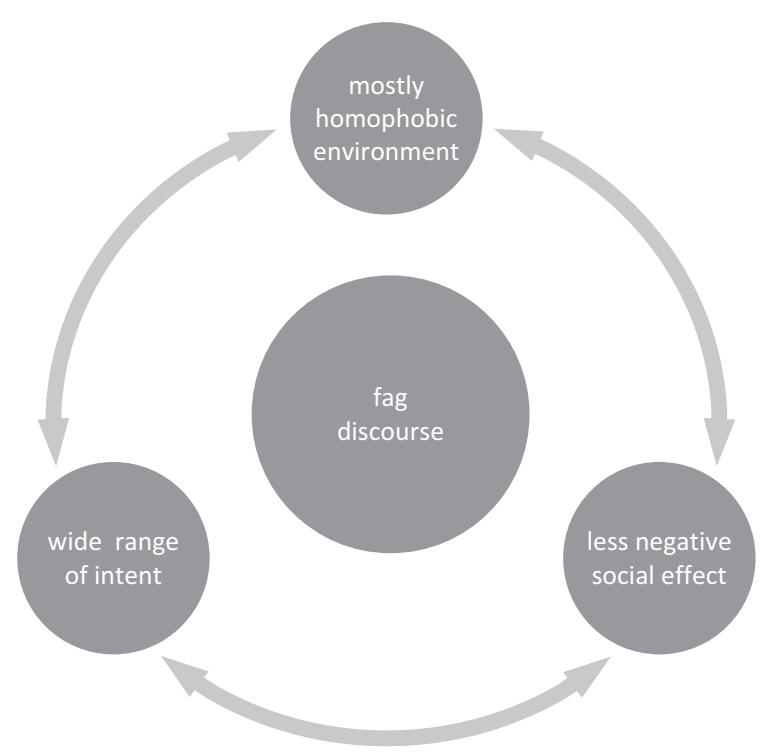

FIGURE 2 A framework for understanding fag discourse. (Color figure available online.)

also documented that many students elected not to use both homophobic and fag discourse. She wrote, "I was stunned at the myriad opportunities to levy the epithet and the seeming refusal by these boys, gay and straight, to invoke it" (p. 79). This is something not documented in previous research (see Mac an Ghaill, 1994) and it is evidence of a less homophobic environment. Accordingly, I conceptualize fag discourse as distinct from homophobic language, as seen in Figure 2.

Pascoe's (2007) work has not been the final development in understanding homosexually-themed language. This is because homophobia has continued to decrease at a rapid rate since Pascoe's study (McCormack, 2011a; Weeks, 2007). While many researchers acknowledge this (Pringle \& Markula, 2005; Swain, 2006), my research has been the first to examine how homosexually-themed language operates in a pro-gay environment.

In an attempt to address this lack of engagement with changing cultural attitudes, I first coauthored an article with Eric Anderson that sought to understand how the effect of homosexually-themed language varied according to the social context (McCormack \& Anderson, 2010a). In this article, we developed the concept of gay discourse to understand the use of language that had a homosexual theme but was not homophobic as described by the frameworks above. This concept emerged from our ethnographic data with heterosexual rugby players who espoused pro-gay attitudes and had openly gay friends but, nonetheless, used phrases like "don't be gay" and "that's so gay." They asserted that this position was consistent because gay had two meanings: it referred to sexuality in some contexts and meant "rubbish" 
in others (see Lalor \& Rendle-Short, 2007), and they argued that the two meanings were wholly independent of each other.

Some scholars continue to argue that the phrase "that's so gay" is homophobic despite decreasing cultural homophobia (see DePalma \& Jennett, 2010; Sanders, 2008). Yet, they do this without critical investigation of the attitudes of those using the language. As a result, they tend to misattribute the phrase as homophobic because they do not engage with attitudes toward homosexuality. Equally problematic, they tend not to engage with how students interpret this discourse (see Adams, Anderson, \& McCormack, 2010 and Lalor and Rendle-Short, 2007 for notable exceptions).

In this rugby research, Anderson and I explained this use of language by viewing the phenomenon through Ogburn's (1950) lens of cultural lag. Cultural lag occurs when two related social variables become dissociated because their meanings change at different rates. In this case, adolescents employ this language without consideration or even knowledge of what it once conveyed. In other words, these rugby players' use of language lagged behind their pro-gay attitudes. Accordingly, we felt the need to develop a new way of understanding their language, one that did not position the participants as implicit homophobes. Our concept, gay discourse, ameliorated this issue by arguing that while implicitly privileging heterosexuality, the language did not have the negative social effects of either homophobic language or fag discourse. Figure 3 conceptualizes this in a way that draws out the difference from homophobic language. With a more inclusive environment and an absence of pernicious intent, the social effects of this language are far less negative.

This framework was useful in understanding the dynamics and implications of the phrase "that's so gay." In order to understand the limited extent of this negative effect, it is important to recognize that the word gay has been used as an expression of displeasure without intent to reflect or transmit homophobia in many contemporary youth settings (Adams, Anderson, \& McCormack, 2010; Lalor \& Rendle-Short, 2007; McCormack, 2011c; McCormack \& Anderson, 2010b). This means that when young people hear the phrase, they do not automatically associate it with homosexuality and it is not necessarily the case that the expression of dissatisfaction translates to negative feelings about same-sex desires or gay people.

The lack of negative social effect is also found in sport settings. Anderson's (2011) most recent examination of the experiences of openly gay male athletes finds that they do not attribute anti-gay sentiment to the phrase "that's so gay." Indeed, one of his respondents argued that, "You can't judge homophobia that way ... The word has different meanings and most of the time it's not got anything to do with gay" (p. 260). Furthermore, all of his participants argued that use of the words gay and fag were not indicative of homophobia. They also did not use the prevalence of the word as a determining factor when deciding to come out. Accordingly, the negativity 


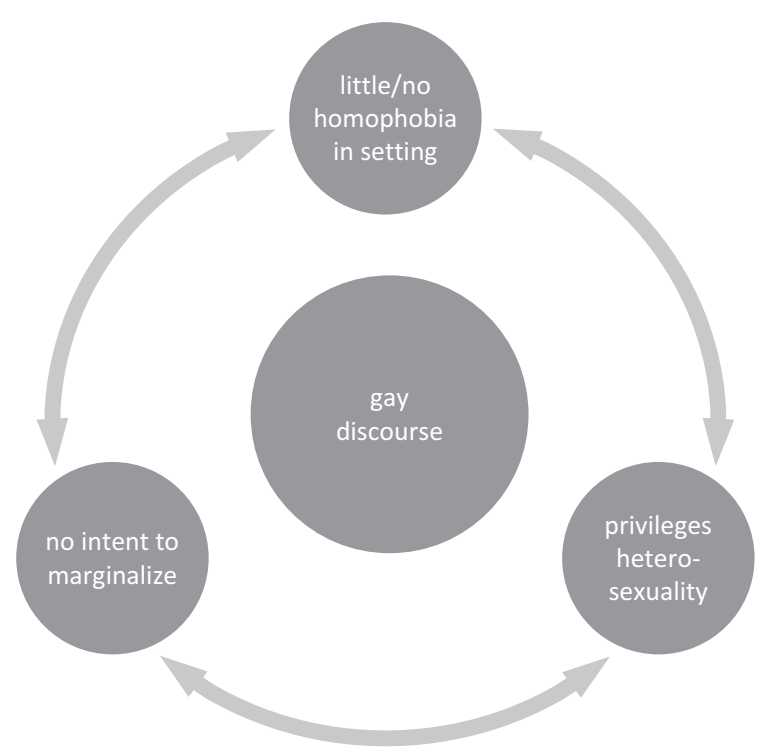

FIGURE 3 A new framework for understanding gay discourse. (Color figure available online.)

from the use of homosexually-themed language has been expunged in these instances.

\section{PRO-GAY LANGUAGE}

While gay discourse was a powerful concept to understand the prevalence of "that's so gay," it was less effective in explaining another use of homosexually-themed language. In my coauthored article on rugby players (McCormack \& Anderson, 2010b), we found that many of these heterosexual men used homosexually-themed language as a form of social bonding. In greeting one another, the men would often say "hey gay boy" or "hey sister." This language was used between friends in a welcoming manner. We argued that this could continue to privilege heterosexuality because of the framework of homosexual stigma that used to exist in rugby. Unfortunately, we were falling back on the same assumption of context that we accused others of doing in labeling "that's so gay" as homophobic: a position that was aided by the fact that there were no openly gay athletes to judge this use of language. Still, we did not have evidence that this privileged heterosexuality and should not, therefore, have drawn the conclusions that we did. I address this issue in my forthcoming book (McCormack, 2011a), where I examine the use of homosexually-themed language between gay and straight students and explore the social effects of this language. 
In this book I conceptualize pro-gay language as a way of understanding homosexually-themed language that has a positive social effect. I defined it as "the use of homosexually-themed language that is used to bond people together in socio-positive ways or to demonstrate pro-gay attitudes." In this research on three high schools in the United Kingdom, I documented that gay and straight male students used pro-gay discourse as a way of bonding. One example of this occurred in an English lesson, when openly gay student, Max, was working with his heterosexual friends, Cooper and James. While Cooper was doodling in his book, he looked up and asked, "Is this really gay what I'm doing?" Max started laughing, and said, "Yeah, it's pretty gay." This was just one example of pro-gay discourse not only bonding students together, but also expunging some of the negativity from these words. Interestingly, this again supports the heterosexual rugby players' contention that their language use was not homophobic (McCormack \& Anderson, 2010a): At the time, Anderson and I argued that the negative social effect of their banter was questionable because no gay peers were around to interpret their language, yet, this finding would suggest that any negative impact is minimal.

In my book (McCormack, 2011a), I also documented a second form of pro-gay language, one where heterosexual male students casually call their close friends "lover" or "boyfriend." Students enacted this language out of homosocial affection, without any discernible attempt to consolidate their heterosexual standing. Proclaiming close friends as boyfriends was understood by the students as a way of demonstrating emotional intimacy. Importantly, these students did not think that labeling each other this way would homosexualize them. The ability for boys to express their emotions in such an open way is clearly a positive development. Moreover, just as homophobic language once contributed to a homophobic school environment, this form of pro-gay language now helps promote gay friendly cultures of inclusivity.

\section{A MODEL OF HOMOSEXUALLY-THEMED DISCOURSE}

In this section, I present an empirically grounded model for conceptualizing all forms of homosexually-themed language. In my new model, I foreground the importance of the cultural context in understanding language. This is because the social environment is pivotal in discerning the intent of language, how it is interpreted and the social effects it has. To explain this, I highlight that no phrase is necessarily part of a particular category. For example, when I was a closeted school student I heard the phrase "that's so gay" frequently, and it was one of the reasons I decided to stay in the closet: I interpreted the phrase as deeply homophobic and it had negative emotional effects on me. Yet, I attended a highly homophobic school where 
the phrase was heard alongside homophobic pejoratives such as "poof," "shirtlifter," and "bender." However, students at the same school today will experience the same phrase very differently (McCormack, 2011a). The point is that the phrase "that's so gay" is not necessarily homophobic, nor does it have to be part of gay discourse-the categorization of language will depend on the cultural context. In order to explore the importance of context in more depth, I turn to Anderson's (2009) concept of homohysteria.

Homohysteria is defined as the cultural fear of being homosexualized. Two key factors affect the level of homohysteria: the homophobia of a culture and the awareness that homosexuality exists within the culture. More specifically, in highly homohysteric cultures, there is an awareness that anyone can be gay. In homohysteric settings, the stigma attached to homosexuality results in men deploying homophobia in an attempt to prove their heterosexuality. Anderson (2009) argues that as homohysteria declines, boys no longer care about being socially perceived as gay and they are afforded a greater range of gendered behaviors. This is something I documented in three British school settings (McCormack, 2011b, 2011c). Homohysteria is a useful concept here because it explains how homophobia is central to construction of masculinity in particular historical times and social contexts (Ibson, 2002). Accordingly, I argue that homohysteria is the key factor in determining the type of social environment, and I now develop my model in relation the homohysteria of a setting.

\section{RELATING THE MODEL TO HOMOHYSTERIA}

In Figure 4, I situate cultural context as central to understanding and categorizing types of homosexually-themed language. First, in a highly homohysteric culture, boys use homophobic language to consolidate their own heterosexual identity and masculine standing (Plummer, 1999). In this stage, homosexually-themed language is indeed homophobic, as it is used with pernicious intent and has a very negative social effect.

The second framework, fag discourse, occurs in settings that are slightly less homohysteric. Here, it is likely that many gay people have negative experiences in sport and schools, and the setting will be homophobic. But it is also likely that there will be people who support gay rights. In this stage, some young men who use fag discourse will insist that it is not meant to stigmatize homosexuality, while others will use it with pernicious intent. However, it will continue to have negative social effects, including the regulation and restriction of acceptable masculine behaviors, because the intent of language use is not always clear (Anderson, 2002).

In the third framework, gay discourse occurs in settings where young men are not particularly concerned about whether they are socially perceived as gay. In settings of low homohysteria, boys say phrases like "that's 

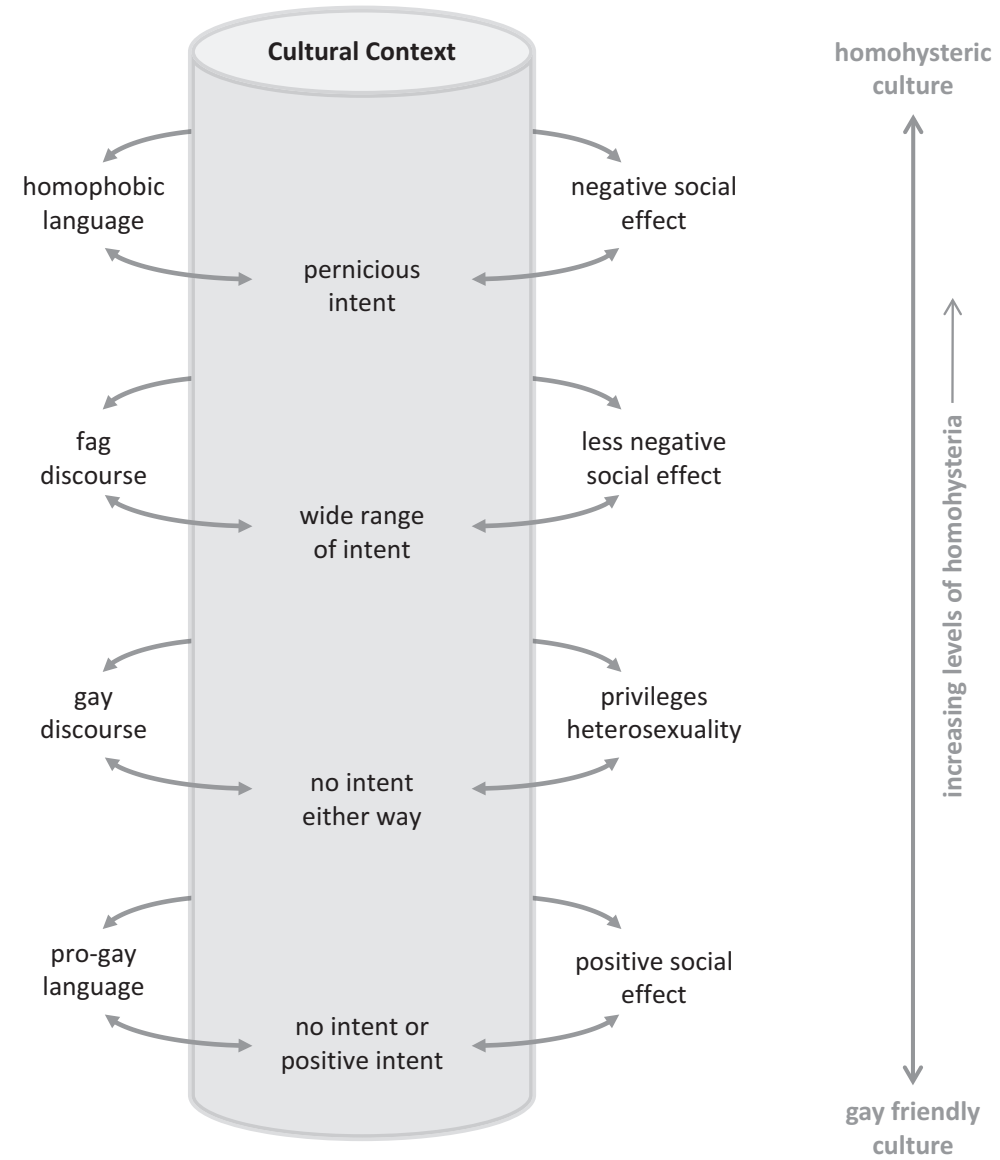

FIGURE 4 A model of homosexually-themed language. (Color figure available online.)

so gay" as expressions of dissatisfaction and frustration. Importantly, there is no intent to marginalize or wound people with the use of this language. While this is not necessarily pro-gay, young men maintain that the word gay does not connote same-sex desire in this context.

Finally, in gay friendly cultures (see McCormack, 2011a), men are not part of a homohysteric culture. While they might prefer to be thought heterosexual, they do not police their behaviors to live up to a heteromasculine ideal. Here, homosexually-themed language is used in a way that has positive social effects. Sometimes pro-gay language is said without any specific intention, but it is also used as a mechanism for bonding students by demonstrating emotional intimacy or inclusion of openly gay students. The fun and fundamentally friendly way this language is used-that is, the ease these students have with gay peers-helps contribute toward a gay friendly environment. 
It is worth emphasizing that use of language is always complex and tricky. There will be some overlap between types of language, as well as exceptions to the framework. For example, while a person can use homophobic language in a gay friendly setting, this would be an anomalous result and would not fit with general conceptualizations of homophobic language in the wider literature. For example, if a student were to shout "you fucking poof" at another boy on a gay friendly sports team, it is highly likely that athlete would be reprimanded by both his fellow teammates and the coach; and, apart from the impact it would have on the recipient, it would have marginal if any negative social effect on the broader culture. Likewise, saying "that's so gay" in a highly homophobic setting would probably be interpreted as homophobic, while it would not in a gay friendly setting. In understanding this form of language, context is all-important (see Davies, 1999; McCormack \& Anderson 2010a).

It should also be noted that Figure 4 does not provide an exhaustive list of words or phrases with a homosexual theme. It does, however, provide a framework by which to judge other forms of language. One example of this is the phrase "no homo." Originating in hip-hop culture, it has received commentary in the media from leading scholars such as Pat Griffin and Michael Kimmel (see also, Brown, 2011). No homo is used when men transgress traditional heteromasculine boundaries as a way of consolidating their heterosexual identities-this is something I call "heterosexual recuperation" (McCormack \& Anderson, 2010b). In her blog, Griffin (2009) is particularly scathing about this use of language, viewing it as homophobic language and saying, "these words can become weapons that provoke fragile peers to suicide or murder." However, drawing on Pascoe's (2007) work, Kimmel (2009) suggests that "no homo" is a sign of progress, writing that no homo "reflects the significant decline in homophobia among straight men in the United States today."

In my model, I suggest that no homo is akin to gay discourse. As Kimmel (2009) argues, there is no actual intent to stigmatize feminine behaviors or homosexuality-just a recognition that a particular behavior might code a person as gay. Indeed, it can even be used as a technique to expand heteromasculine boundaries (see McCormack \& Anderson, 2010b), effectively enabling someone to say "I'm straight, but I love you." Indeed, one could argue whether it is homosexually-themed at all, that it is not instead just a statement of one's own heterosexuality (an issue I have examined elsewhere [McCormack, 2011a] is how pro-gay heterosexual men demonstrate their heterosexuality without being homophobic). But this nitpicking aside, while no homo privileges heterosexuality, it is hard to see it as homophobic. Accordingly, this model can be used as a framework to understand new manifestations of homosexually-themed language as they arise. 


\section{CONCLUSION}

In this article, I have examined the use of homosexually-themed language as it is discussed in the academic literature. By comparing the language used in settings of homophobia with that of sites where homophobic language is absent, I developed a four-stage model to historically and spatially situate the use of language and how it is and should be interpreted. It is my hope that this new model will help teachers, students, and scholars understand and identify different forms of homosexually-themed language. Hopefully, by categorizing it appropriately, we can ensure that we are all more able to appropriately judge the extent to which particular settings (be they sport based, educational, or more general) are homophobic, gay friendly, or somewhere in between.

\section{REFERENCES}

Adams, A., Anderson, E., \& McCormack, M. (2010). Establishing and challenging masculinity: The influence of gendered discourses in organized sport. Journal of Language and Social Psychology, 29, 278-300.

Anderson, E. (2002). Openly gay athletes: Contesting hegemonic masculinity in a homophobic environment. Gender E Society, 16, 860-877.

Anderson, E. (2005). In the game: Gay atbletes and the cult of masculinity. Albany, NY: State University of New York Press.

Anderson, E. (2009). Inclusive masculinity: The changing nature of masculinities. New York, NY: Routledge.

Anderson, E. (2011). Updating the outcome: Gay athletes, straight teams, and coming out in educationally based sport teams. Gender \& Society, 25(2), 250-268.

Anderson, E., \& McGuire, R. (2010). Inclusive masculinity theory and the politics of men's rugby. Journal of Gender Studies, 19, 249-262.

Armstrong, J. D. (1997). Homophobic slang as coercive discourse among college students. In A. Livia \& K. Hall (Eds.), Queerly phrased: Language, gender and sexuality, (pp. 326-334). New York, NY: Oxford University Press.

Bortolin, S. (2010). "I don't want him hitting on me": The role of masculinities in creating a chilly high school climate. Journal of LGBT Youth, 7, 200-223.

Brackenridge, C., Allred, P., Jarvis, A., Maddocks, K., \& Rivers, I. (2008). A literature review of sexual orientation in sport. London, UK: UK Sport.

Cameron, D., \& Kulick, D. (2003). Language and sexuality. Cambridge, UK: Cambridge University Press.

Davies, C. A. (1999). Reflexive ethnography: A guide to researching selves and others. London, UK: Routledge.

D’Augelli, A., Hershberger, S. L., \& Pilkington, N. W. (2001). Suicidality patterns and sexual orientation-related factors among lesbian, gay, and bisexual youths. Suicide and Life-Threatening Behavior, 31, 250-264. 
DePalma, R., \& Jennett, M. (2010). Homophobia, transphobia and culture: Deconstructing heteronormativity in English Primary schools. Intercultural Education, 21, 15-26.

Epstein, D. (1997). Boyz' own stories: Masculinities and sexualities in schools. Gender and Education, 9, 105-115.

Flowers, P., \& Buston, K. (2001). "I was terrified of being different": Exploring gay men's accounts of growing-up in a heterosexist society. Journal of Adolescence, 24, 51-65.

Griffin, P. (1998). Strong women, deep closets: Lesbians and homophobia in sport. Champaign, IL: Human Kinetics.

Griffin, P. (2009, November 9). No homo! No dumbo. Pat Griffin's LGBT sport blog. Retrieved from http://ittakesateam.blogspot.com/2009/11/no-homo-nodumbo.html

Harris, J., \& Clayton, B. (2007). The first metrosexual rugby star: Rugby union, masculinity, and celebrity in contemporary Wales. Sociology of Sport Journal, 24, 145-164.

Hekma, G. (1998). "As long as they don't make an issue of it . . ." Gay men andlesbians in organized sports in the Netherlands. Journal of Homosexuality, $35,1-23$.

Hillier, L., \& Harrison, L. (2004). Homophobia and the production of shame: Young people and same-sex attraction. Culture, Health \& Sexuality, 6, 79-94.

Ibson, J. (2002). Picturing men: A century of male relationships in everyday life. Washington, DC: Smithsonian Books.

Jackson, C., \& Dempster S. (2009). "I sat back on my computer . . with a bottle of whisky next to me": Constructing "cool" masculinity through "effortless" achievement in secondary and higher education. Journal of Gender Studies, 18, 341-356.

Kiesling, S. F. (2007). Men, masculinities, and language. Language and Linguistics Compass, 1, 653-673.

Kimmel, M. S. (2008). Guyland: The perilous world where boys become men. New York, NY: Harper Collins.

Kimmel, M. S. (2009, November 5). From "that's so gay" to "no homo": A small sign of progress. The Huffington Post. Retrieved from http://www.huffingtonpost. com/michael-kimmel/from-thats-so-gay-to-no-h_b_345390.html

Lalor, T., \& Rendle-Short, J. (2007). "That's so gay": A contemporary use of gay in Australian English. Australian Journal of Linguistics, 27, 147-173.

Loftus, J. (2001). America's liberalization in attitudes towards homosexuality, 1973-1998. American Sociological Review, 66, 762-782.

Mac an Ghaill, M. (1994). The making of men: Masculinities, sexualities and schooling. Buckingham, UK: Open University Press.

McCormack, M. (2011a). Teen masculinities: How young men are redefining beterosexuality and masculinity. New York, NY: Oxford University Press.

McCormack, M. (2011b). Hierarchy without hegemony: Locating boys in an inclusive masculinity school setting. Sociological Perspectives, 54, 83-101.

McCormack, M. (2011c). The declining significance of homohysteria for male students in three sixth forms in the south of England. British Educational Research Journal, 37, 337-353. 
McCormack, M., \& Anderson, E. (2010a). The re-production of homosexuallythemed discourse in educationally based organized sport. Culture, Health $\varepsilon$ Sexuality, 12, 913-927.

McCormack, M., \& Anderson, E. (2010b). "It's just not acceptable any more": The erosion of homophobia and the softening of masculinity at an English sixth form. Sociology, 44, 843-859.

Messner, M. (1992). Power at play: Sports and the problem of masculinity. Boston, MA: Beacon Press.

Mustanski, B. S., Garofalo, R., \& Emerson, E. M. (2010). Mental health disorders, psychological distress, and suicidality in a diverse sample of lesbian, gay, bisexual, and transgender youths. American Journal of Public Health, 100, 2426-2432.

Ogburn, W. F. (1950). On culture and social change. Chicago, IL: Chicago University Press.

Parker, A. (1996). The construction of masculinity within boys' physical education. Gender and Education, 8, 141-157.

Pascoe, C. J. (2005). "Dude, you're a fag": Adolescent masculinity and the fag discourse. Sexualities, 8, 329-346.

Pascoe, C. J. (2007). Dude, you're a fag. London, UK: University of California Press.

Plummer, D. (1999). One of the boys: Masculinity, homophobia and modern manhood. New York, NY: Harrington Park Press.

Pringle, R., \& Markula, P. (2005). No pain is sane after all: A Foucauldian analysis of masculinities and men's experiences in rugby. Sociology of Sport Journal, 21, 472-497.

Pronger, B. (1990). The arena of masculinity: Sports, bomosexuality, and themeaning of sex. New York, NY: St. Martin's Press.

Rasmussen, M. L. (2004). "That's so gay!": A study of the deployment of signifiers of sexual and gender identity in secondary school settings in Australia and the United States. Social Semiotics, 14, 289-308.

Rivers, I. (1995, March). The victimization of gay teenagers in schools: Homophobia in education. Pastoral Care, 35-41.

Rivers, I. (1996). Protecting the gay adolescent at school. Medicine, Mind and Adolescence, 11(2), 15-24.

Rubin, G. (1984). Thinking sex: Notes for a radical theory of the politics of sexuality. In C. Vance (Ed.), Pleasure and danger: Exploring female sexuality (pp. 34-78). Boston, MA: Routledge.

Sanders, S. (2008). Tackling homophobia, creating safer spaces. In R. dePalma \& E. Atkinson (Eds.), Invisible boundaries: Addressing sexualities equality in children's worlds (pp. 3-12). Stoke-on-Trent, UK: Trentham.

Savin Williams, R. C. (2005). The new gay teenager. London, UK: Harvard University Press.

Smith, J. (2007). "Ye've got to 'ave balls to play this game sir!" Boys, peers and fears: the negative influence of school-based "cultural accomplices" in constructing hegemonic masculinities. Gender and Education, 19, 179-198.

Swain, J. (2006). Reflections on patterns of masculinity in school settings. Men and Masculinities, 8, 331-349.

Thorne, B., \& Luria, Z. (1986). Sexuality and gender in children's daily worlds. Social Problems, 33, 176-190. 
Thurlow, C. (2001). Naming the "outsider within": Homophobic pejoratives and the verbal abuse of LGB high-school pupils. Journal of Adolescence, 24, 25-38.

Warwick, I., Aggleton, P., \& Douglas, N. (2001). Playing it safe: Addressing the emotional and physical health of lesbian and gay pupils in the U.K. Journal of Adolescence, 24, 129-140.

Weeks, J. (2007). The world we have won. London, UK: Routledge. 